\title{
БИБЛИОТЕРАПИЯ \\ КАК ЭФФЕКТИВНЫЙ МЕТОД РАБОТЫ С ДЕПРЕССИВНЫМИ СОСТОЯНИЯМИ
}

\author{
Пашкина Е.А., Калинина Т.В. \\ ФГАОУ ВО «Национальный исследовательский \\ Нижегородский государственный университет \\ им. Н.И. Лобачевского», Арзамасский филиал, \\ г. Арзамас, Российская Федерация
}

В статье раскрыта проблема депрессивных состояний учащейся молодежи и ее актуальность на сегодняшний день в работе психолого-педагогической службы вуза. Библиотерапия представлена, как один из эффективных арт-терапевтических методов в работе с депрессивными состояниями. Представлено два направления библиотерапии по степени включенности клиента в психотерапевтический процесс. Описан диагностический и терапевтический потенциал библиотерапии. Предпринята попьтка описания использования библиотерапии в работе с деприссивными состояниями современной учамейся молодежи.

Ключевые слова: студенты; депрессивные состояния; арттерапия; библиотерапия.

\section{BIBLIOTHERAPY AS AN EFFICIENT METHOD OF WORKING WITH DEPRESSIVE STATES}

\author{
Pashkina E.A., Kalinina T.V. \\ National Research Nizhny Novgorod State University, \\ Arzamas branch, Arzamas, Russian Federation \\ The article reveals the problem of depressive states of young students \\ and its relevance today in the work of the psychological and pedagogical \\ service of the university. Bibliotherapy is presented as one of the effective \\ art-therapeutic methods in work with depressive states. Two directions \\ of bibliotherapy on the degree of client involvement in the psychothe-
}


rapeutic process are presented. The diagnostic and therapeutic potential of bibliotherapy is described. An attempt has been made to describe the use of bibliotherapy in working with depressive states of modern students.

Keywords: students; depressive states; art therapy; bibliotherapy.

В современном мире человек сталкивается с большим количеством стрессовых ситуаций, испытывает высокий уровень психических и физических нагрузок, переживает различного рода неблагоприятные события. Воздействие этих факторов является причиной возникновения депрессивных состояний, которые могут привести к депрессии. По данным ВОЗ депрессия распространена во всем мире и от нее страдает более 300 млн. человек [4].

В последнее время наблюдается активный рост депрессивных состояний у студентов. Получение образования в ВУЗе можно отнести к специфическому виду деятельности, который связан с необходимостью усваивать большие объёмы различной информации, повышенными требованиями к решению проблемных ситуаций и большими нагрузками. Безусловно, это негативно сказывается на психоэмоциональном и психофизическом состоянии студентов, которое трансформируется в дальнейшем в депрессивные состояния [2].

Исследования депрессивных состояний учащейся молодёжи на базе УрГУПС показывает, что из 120 студентов 1-4 курсов, начальные симптомы развивающейся депрессии выявлены у $36 \%$ первокурсников и у 50\% студентов 4-го курса. Стоит отметить, что среди студентов 4-го курса 2\% имеют ярко выраженное депрессивное состояние [5].

По результатам психодиагностического исследования 109 студентов Медицинской академии им. С.И. Георгиевского ФГАОУ ВО «КФУ им. Вернадского», имеют признаки депрессии более 50\% студентов 1-5 курсов [3].

Опыт работы психологической службы АФ ННГУ им. Н.И. Лобачевского также показывает, что увеличивается количество обращений студентов по вопросу депрессивных состояний, связанных как с детско-родительскими отношениями, так и с проблемами личного характера. В связи с этим, необходимо обеспечить психологи- 
ческое сопровождение студентам, испытывающих депрессивные состояния, чтобы предотвратить переход депрессивных состояний непосредственно в депрессию.

Известно, что искусство и творчество благоприятно воздействует на психоэмоциональное состояние человека. Форма психотерапии и психологической коррекции, основанная на применении разнообразных форм искусства - носит название «арт-терапия». Существует множество видов арт-терапии (музыкотерапия, драматерапия, танцевальная терапия и т.д), но наиболее эффективной, на наш взгляд, в работе с депрессивными состояниями, является библиотерапия.

В традиционном понимании библиотерапия представляет собой использование художественных произведений как поэтических, так и прозаических, созданных поэтами и писателями [6].

По мнению психотерапевта, психиатра Алексейчика А.Е. библиотерапия есть лечебное воздействие с помощью литературы, целью которого является оптимизация и нормализация психических состояний клиента, а через них воздействие на биологические и физиологические процессы организма [1].

Осипова А.А. определяет библиотерапию как специальное коррекционное воздействие на человека при помощи чтения специально подобранной литературы с целью нормализации и оптимизации психического состояния клиента [7].

Библиотерапия отличается от других методов психотерапии характером психотерапевтических процессов. Рассмотрим их некоторые особенности при данном виде терапии. Во-первых, в ходе работы с клиентом, формируем процесс успокоения, который он может получить, основываясь на авторитетные и специфические знания о своей проблеме из научной литературы. Такое же успокаивающее воздействие оказывает и специально подобранная художественная, публицистическая, или философская литература. Алексейчик А.Е. указывал на то, что клиенту, имеющему тревожные мысли о своём будущем, полезно чтение произведения А. Герцена «Былое и думы», где слова автора о несчастьях, не оставляют никакой горечи на душе, а лишь укрепляют молодую жизнь своими 
ударами, успокаивают клиента и помогают ему приобрести уверенность в решении своих проблем [1].

Во-вторых, клиент, пребывающий в депрессивном состоянии, чувствует себя отделённым от окружающих людей и от мира своей проблемой, что ограничивает его в получении удовольствия.

В ходе использования библиотерапии клиент посредством чтения хорошей книги получает это необходимое дополнительное удовольствие. Поэтому важно подобрать литературу имеющую психотерапевтический эффект с учётом жанровых предпочтений клиента [7].

В-третьих, библиотерапия помогает сформировать у клиента чувство уверенности в себе и веру в собственные возможности. Такой эффект приносит чтение автобиографий, биографий, воспоминаний выдающихся личностей с нелёгкой судьбой. Клиент, пребывающий в депрессивном состоянии, читая такую литературу, начинает видеть, что великие люди также переживали трудности, и находить много общего с ними, тем самым минимизируя актуальность собственной проблемы. К таким произведениям можно автобиографические произведения Л. Толстого («Исповедь», «Путь жизни»), Ф. Достоевского («Записки из мертвого дома», «Дневник писателя»), А. Чехова («Письма») и мн. другие [1].

И, наконец, в-четвёртых, большинство литературных жанров могут вызвать высокую психическую активность, которая стимулирует у клиента активизацию защитных психических механизмов, что способствует исчезновению травмирующих переживаний, а также способствует творческому преодолению трудностей клиентом [7].

В настоящее время большое количество арт-терапевтов применяют самостоятельно написанные сочинения, а так же ведение клиентами личных дневников. В рамках данного подхода библиотерапию можно определить как направление арт-терапии, которое основано на исцеляющем воздействии слова, иными словами самовыражение через творческое сочинение [6].

Стоит отметить значительный диагностический и терапевтический потенциал библиотерапии. Так как основу речи составляет вторая сигнальная система, то из сочинения клиента можно узнать о том, как на самом деле он живёт, что чувствует и что переживает в тот, или иной 
момент жизни. Художественное сочинение дает возможность клиенту опосредованно, используя метафоры, образы, устойчивые выражения написать о своих проблемах и точнее охарактеризовать своё душевное состояние. Стоит отметить, что автор является главным героем произведения. Излагая на листе бумаги и проговаривая свою проблему, клиент высвобождается от негативных эмоций и переживаний, что способствует снижению уровня тревожности и напряжения.

Творческое сочинение имеет множество вариантов, например: рассказ, стихосложение, рассказ на заданную тему, письма, автобиография вымышленного персонажа, драматургия, автобиография в виде литературного произведения, а также написание любого жанра литературного произведения по чётким законам [6].

Таким образом, библиотерапия является одним из эффективных арт-терапевтических методов в работе с депрессивными состояниями учащейся молодёжи. Диагностический потенциал библиотерапии позволяет найти причины возникновения проблемы, и помогает клиенту вербализировать своё душевное состояние. Широкий спектр разнообразия жанров, возможность использовать в процессе психотерапии, как произведения клиента, так и произведения других авторов, позволяет найти индивидуальный подход к клиенту, основываясь на его интересах и предпочтениях.

\section{Список литературы}

1. Алексейчик А.Е. Библиотерапия // Руководство по психотерапии / Под ред. В.Е. Рожнова. Т.: Медицина, 1985. С. 304-319.

2. Веретенников В.Л. Коррекция психофизического состояния студентов на основе интегрального показателя адаптированности к обучению в вузе / В.Л. Веретенников // Ученые записки университета им. П.Ф. Лесгафта. 2011. №10(80). 51 с.

3. Гуменюк Л.Н. Связь психологического благополучия с тревожными и депрессивными состояниями у студентов / Л.Н. Гуменюк [и др.] // образование и наука в России и за рубежом. 2018. №5. С. 115-119.

4. Депрессия: [Электронный ресурс] // Всемирная организация здравоохранения. URL https:/www.who.int/ru/news-room/fact-sheets/detail/ depression/. (Дата обращения: 13.02.2019). 
5. Ершова А.В. Депрессивное состояние у студентов и его влияние на мотивационную составляющую к учебной деятельности / А.В. Ершова // Университетский комплекс как региональный центр образования, науки и культуры. Материалы Всероссийской научнометодической конференции. 2014. С. 3960-3963.

6. Колошина Т. Ю., Трусь А. А. Арт-терапевтические техники в тренинге: характеристики и использование. Практическое пособие для тренера // Т.Ю. Колошина, А.А. Трусь. СПб.: Речь, 2010. 189 с.

7. Осипова А.А. Общая психокоррекция. Учебное пособие. М.: Сфеpa, $2002.510 \mathrm{c}$.

\section{References}

1. Alekseychik A.E. Biblioterapiya // Rukovodstvo po psikhoterapii / Pod red. V.E. Rozhnova. T.: Meditsina, 1985. S. 304-319.

2. Veretennikov V. L. Korrektsiya psikhofizicheskogo sostoyaniya studentov na osnove integral'nogo pokazatelya adaptirovannosti k obucheniyu v vuze / V.L. Veretennikov // Uchenye zapiski universiteta im. P.F. Lesgafta. 2011. №10(80). $51 \mathrm{~s}$.

3. Gumenyuk L.N. Svyaz' psikhologicheskogo blagopoluchiya s trevozhnymi i depressivnymi sostoyaniyami u studentov / L.N. Gumenyuk [i dr.] // obrazovanie i nauka v Rossii i za rubezhom. 2018. №5. S. 115-119.

4. Depressiya: [Elektronnyy resurs] // Vsemirnaya organizatsiya zdravookhraneniya. URL https://www.who.int/ru/news-room/fact-sheets/detail/ depression/ (Data obrashcheniya: 13.02.2019).

5. Ershova A.V. Depressivnoe sostoyanie u studentov i ego vliyanie na motivatsionnuyu sostavlyayushchuyu k uchebnoy deyatel'nosti / A.V. Ershova // Universitetskiy kompleks kak regional'nyy tsentr obrazovaniya, nauki i kul'tury. Materialy Vserossiyskoy nauchno-metodicheskoy konferentsii. 2014. S. 3960-3963.

6. Koloshina T.Yu., Trus' A.A. Art-terapevticheskie tekhniki v treninge: kharakteristiki i ispol'zovanie. Prakticheskoe posobie dlya trenera // T.Yu. Koloshina, A.A. Trus'. SPb.: Rech', 2010.189 s.

7. Osipova A.A. Obshchaya psikhokorrektsiya. Uchebnoe posobie. M.: Sfera, 2002. $510 \mathrm{~s}$. 